\title{
3D Printing and Education
}

\author{
Eugenia Arvanitidi \\ Dept. of Industrial Design \\ and Production \\ Engineering \\ UNI.W.A \\ Athens, Greece
}

\author{
Christos Drosos, PhD \\ Dept. of Industrial Design \\ and Production \\ Engineering \\ UNI.W.A \\ Athens, Greece
}

\author{
Eystathios \\ Theocharis \\ Dept. of Industrial Design \\ and Production \\ Engineering \\ UNI.W.A \\ Athens, Greece
}

\author{
Michail \\ Papoutsidakis, PhD \\ Dept. of Industrial Design \\ and Production \\ Engineering \\ UNI.W.A \\ Athens, Greece
}

\begin{abstract}
$3 \mathrm{D}$ printing is a great revolution, and its presence is getting stronger in industry and education. The three-dimensional printing process starts by feeding the $3 \mathrm{D}$ printer with print material, making sure that the material is chosen to suit the needs of the print object. It then prepares, adjusts and clears the print surface, and once the digital 3D drawing is transferred to the printer, the machine automatically creates the desired 3D object. Three-dimensional printing and the surrounding environment make it easier for learners to learn more complex concepts and provide them with new "tools". Finally, the proposed Education Program for Educators was based on the philosophy of adult education programs.
\end{abstract}

\section{Keywords}

3D printing, 3D printer, education, adult education, training of trainers.

\section{INTRODUCTION}

The adoption of additive manufacturing (AM) and 3D printing (3DP) technologies in industry is growing as new applications are found that take advantage of their functionalities [1-3]. In this paper we present the technology of $3 \mathrm{D}$ printing and its application in education. In particular, the pedagogical design of an instructor training program for three-dimensional printing.

\section{BACKGROUND}

\subsection{D Printing}

3D printing is an emerging technology that many believe will revolutionize manufacturing, supply chains and global product consumption. 3D printing, or additive manufacturing, is a process of making 3D solid objects from a digital file by building layer upon layer of material. This type of manufacturing process has many advantages over traditional manufacturing in that $3 \mathrm{D}$ printed designs do not become more expensive with complexity, it is very cheap to customize the designs and you can print shapes that are impossible to manufacture through subtractive manufacturing techniques [4]. If the technology develops as many hope, the unique advantages of $3 \mathrm{D}$ printing could have a dramatic impact on the economy [5].

One effect of widespread 3D printer adoption is that it will completely revolutionize business models and global supply chains [6]. Currently, most products are mass produced in a central location and then shipped around the world. If consumers can directly print an object on demand, then traditional manufacturing and supply chains will dramatically change.

Second, 3D printing will change the nature of warehousing and commerce [6]. Manufacturers and retailers will no longer need to maintain backup supplies and consumers will not need to go the store as often to buy products. Rather, if a person needs something, they can simply download and print the item from home. Currently, retail sales people and cashiers are the two largest occupations in the USA accounting for about 4.5 million and 3.5 million jobs respectively. Supply chain jobs, like freight and movers, make up about 2.5 million jobs. Together these occupations are about $7 \%$ of the USA workforce [7]. If 3D printing replaces some of these jobs, that will lead to major economic disruptions around the country.

Third, 3D printers can be more environmentally sustainable than other manufacturing techniques because they use less raw materials, generate fewer wasted byproducts, and is a less energy intensive process [8, 9]. Developing environmental friendly technologies is especially necessary because as the world's population grows, gets wealthier and demands more goods, there will be an increasing desire for limited resources. Without making a dramatic change to manufacturing, the world will quickly run out of raw materials for new goods. An additional benefit of generating less waste is that the lives of poor and marginalized communities, which suffer the majority of ill consequences from waste generation [10-12], will improve.

Specifically, 3-D printing is an additive manufacturing (AM) technique for fabricating a wide range of structures and complex geometries from three dimensional (3D) model data. The process consists of printing successive layers of materials that are formed on top of each other. This technology has been developed by Charles Hull in 1986 in a process known as stereolithography (SLA), which was followed by subsequent developments such as powder bed fusion, fused deposition modelling (FDM), inkjet printing and contour crafting (CC). 3D-printing, which involves various methods, materials and equipment, has evolved over the years and has the ability to transform manufacturing and logistics processes. Additive manufacturing has been widely applied in different industries, including construction, prototyping and biomechanical. The uptake of 3D printing in the construction industry, in particular, was very slow and limited despite the advantages e.g. less waste, freedom of design and automation [13].

A wide range of materials that are currently used in 3D printing include metals, polymers, ceramics and concrete. Polylactic acid (PLA) and acrylonitrile butadiene styrene (ABS) are the main polymers used in the $3 \mathrm{D}$ printing of composites. Advanced metals and alloys are typically utilised in the aerospace sector because traditional processes are more time-consuming, difficult and costly. Ceramics are mainly used in 3Dprinted scaffolds and concrete is the main material employed in the additive manufacturing of buildings. However, the inferior mechanical properties and anisotropic behaviour of 3D printed parts still limit the potential of large- 
scale printing. Therefore, an optimised pattern of 3D priming is important to control flaw sensitivity and anisotropic behaviour. Also, changes in the printing environment have an influence on the quality of finished products [14]. AM is capable of fabricating parts of various sizes from the micro-to macro-scale. However, the precision of the printed parts is dependent on the accuracy of the employed method and the scale of printing. For instance, micro-scale 3D printing poses challenges with the resolution, surface finish and layer bonding, which sometimes require post-processing techniques such as sintering [15]. On the other hand, the limited materials available for $3 \mathrm{D}$ printing pose challenges in utilising this technology in various industries. Hence, there is a need for developing suitable materials that can be used for 3D printing. Further developments are also needed to enhance the mechanical properties of 3D printed parts [13].

Finally, the next figure shows the four main methods of additive manufacturing: (a) fused deposition modelling; (b) inkjet printing; (c) stereolithography; (d) powder bed fusion:

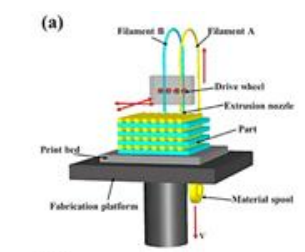

(b)

$$
\text { (c) }
$$

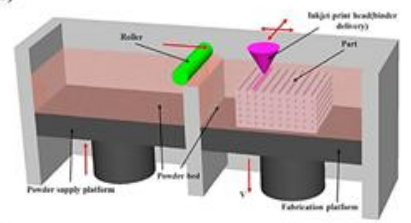

(d)

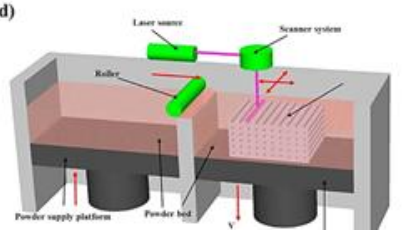

Fig 1: The basic methods of AM

\subsection{Educational Applications}

The sections that follow summarize the four main pedagogical environments in which 3DP is being used: (1) schools; (2) universities; (3) libraries; and (4) special education settings. Specifically:

- 3D printing in schools: The 3DE with prototype design can provide the basis for improving understanding of science and mathematics [16]. The $3 \mathrm{DE}$ is used to support STEM education in schools.

- - Higher Education: Higher education, higher education is higher in universities (Table 3), and there are relatively few reports on the adoption of technology in other continuing education and training institutions. The international literature cites 3DE applications at universities that have to do with the creation of threedimensional printer systems, scientific models and test models. It is also used during project-based learning, in the introduction to $3 \mathrm{DE}$ development curricula by integrating it into existing courses or by creating new courses. In particular, $3 \mathrm{DE}$ can be used to create test models for experiments. This also includes test specimens for learning the mechanical properties of materials [17]. There are generally undergraduate and postgraduate courses for $3 \mathrm{DE}$ in many universities around the world as an independent field of knowledge or as a supportive tool in other related subjects $[18,19]$.

- Libraries: in the international literature, it seems that the use of 3DE in school libraries, universities, vocational colleges, public libraries, medical libraries and libraries

in general are positive. The issue of adopting 3DE in libraries lies within a wider debate on the nature of libraries in a digital age. Some criticize 3DE for being used in libraries, since they claim to be an "exotic cutting edge technology based on technology and a simple extravagance that requires unnecessary expenses ..."[2022]. However, the majority of scholars have a positive attitude towards the incorporation of 3DE into library services. A more representative statement is that "... in most organizations, the library is a rational choice to host technology. Providing space and expertise for 3D printing, it can provide a valuable service to its organization while also upgrading its other services ....". As a physical space, libraries offer opportunities for collaboration and knowledge sharing among library users, librarians and trainers, and reduce barriers to participation. This accessibility has become apparent in libraries as creative sites, where 3D printers, among other digital technologies, are available to library sponsors that encourage creativity and experimentation [17].

- 3D Printing in Special Educational Environments: Used in special educational environments for those with visual, motor and cognitive disorders, kinetic and cognitive impairments, along with combinations of the previous ones. The use of $3 \mathrm{DE}$ involves the creation of customized devices and training aids that provide greater participation of these students in STEM objects. The use of the $3 \mathrm{D}$ printer in special educational environments is not without its challenges as described in various studies. Students' interest in finalizing designs with a 3D printer seems to be diminishing due to the challenge of using the software. In addition, three-dimensional design capability is difficult for students with high support needs. Several professional therapists who worked with students in some research while delighted with the potential of 3DE were worried about the effort needed to learn how to use the software $[17,23,24]$.

There are six main ways in which 3DP is being used: (1) to teach students about 3DP; (2) to teach educators about 3DP; (3) as a support technology during teaching; (4) to produce artifacts that aid learning; (5) to create assistive technologies; and (6) to support outreach activities. The curricula into which this 3DP teaching has been actively integrated is summarized in Table 1. In these accounts, the stated learning objectives of the introduced 3DP teaching content ranges from the very brief and general to the more detailed and specific [17].

Table 1. Summary of university courses into which 3DP teaching has been actively integrated

Subject
Computer graphics
Design and manufacturing with polymers
Engineering design
General engineering
Graphic design
Industrial engineering and business
Informatics
Mechanical design and manufacturing processes
Product and industrial design
Product development
Product realization


In broad terms, 3DP courses are being introduced to encourage creative experimentation; enable product innovation and entrepreneurship; support the integration of technical knowledge from other courses; and facilitate multiand interdisciplinary approaches. More specifically, the stated objectives of these courses is to develop a range of technical and nontechnical 3DP-related skills [17]. These learning objectives are summarized in Table 2.

Table 2. Summary of university courses into which 3DP teaching has been actively integrated

Learning objectives of 3DP-focused courses.

\begin{tabular}{l} 
Learning objective \\
Appreciate the advantages and disadvantages of 3DP technologies \\
Appreciate the differences between 3DP and conventional manufacturing processes \\
Evaluate the performance and functional constraints of 3DP for specific applications \\
Learn and apply 3DP post-processing techniques \\
Learn and apply design for 3DP principles \\
Learn and use 3D scanners \\
Recognise business opportunities for 3DP \\
Recognise current and future 3DP applications \\
Recognise important 3DP research challenges \\
Understand and recognise the causes of errors and irregularities in 3DP parts \\
Understand the complete 3DP sequence of designing, fabricating and measuring parts \\
Understand the fundamentals of 3DP and its basic operating principles \\
\hline
\end{tabular}

Finally, 3DP is frequently used in design projects. The range of artifacts created during such projects is highly diverse and examples are included in Table 3. In addition of these artifacts, 3D printers themselves have been built during integrated engineering design and mechatronics and instrumentation projects [17].

Table 3. 3D printed artifacts created during design projects

\begin{tabular}{l}
\hline Artefacts \\
\hline Biomedical devices \\
Bridges \\
Desk lamps \\
Exoskeletons \\
Home appliances \\
Microfluidics \\
Model cars \\
Musical instruments \\
Orthotics \\
Quadcopters \\
Robots \\
Rockets \\
Unmanned aircraft system wings \\
Whistles
\end{tabular}

\section{PROPOSED EDUCATIONAL PROGRAM}

The general educational aim of the proposed program is to train people as adult educators in the subject of $3 \mathrm{D}$ printing and their applications. In particular, adult learner and adult educators, after monitoring the program, will be able to:

- to train in an innovative, creative and efficient way,

- coordinate the actions of the trained team,
- $\quad$ design, execute and evaluate the teaching and learning process,

- develop a positive emotional climate in the learning group, which will guarantee communication and collaboration,

- to provide specific knowledge in the field of 3DE, and

- provide specialist knowledge in the design and implementation of three-dimensional printing applications

The teaching objectives of the program are divided into three levels according to the literature [25-27]:

- knowledge that learners will receive from the program,

- $\quad$ skills / skills that learners will develop after the end of the program, and

- Attitudes that learners will adopt for the subject in which they are trained (3DP).

The target population of the program is graduates of higher education, positive and technological sciences, with adult education experience, without the latter being a mandatory criterion. As far as the content of the proposed curriculum is concerned, following the educational purpose and objectives, it can be divided into two levels (Figure 2):

- pedagogical training: this includes the knowledge / skills and attitudes related to the teacher's context from a pedagogical point of view, and includes the following modules:

- Theoretical framework of Adult Education \& STEM

- Adult Education Planning

- Educational Techniques and Team Dynamics

$\circ \quad$ Teaching-practice

- technical training: this includes the knowledge / skills and attitudes related to the 3DE cognitive field and includes the following modules:

○ Introduction to 3D Printing

○ Technology of 3D Printer

○ 3D Design

$\circ \quad$ 3D Printing Applications

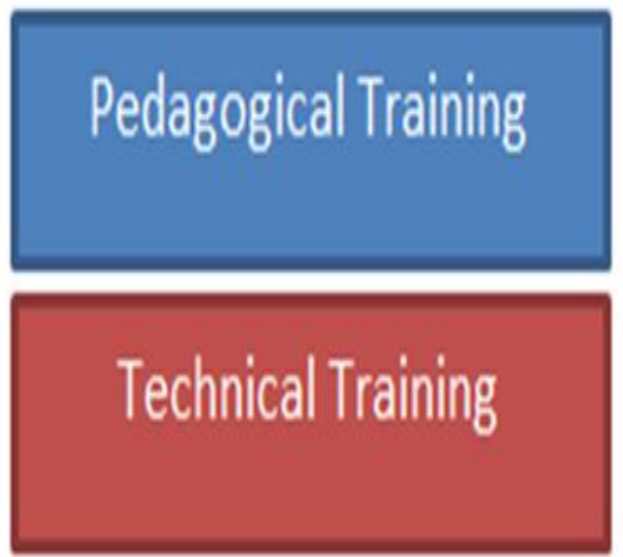

Fig 2: Adult Education Program Content Structure 
The structure of the modules is configured so that the educational material can:

- guides the trainee in his study,

- promotes learner interaction with learning material,

- Explains difficult concepts and issues,

- Evaluates and informs the learner about progress / improvement,

- Specialize in theoretical knowledge with the appropriate use of practical exercises / applications.

In particular, for the proposed program, each trainer can use whatever method he considers useful so that the greatest learning outcomes can be achieved (lecture, simulation, case study etc.). Also, in the program, the type of rectangle is chosen because it facilitates enough the use of educational techniques (even collaborative-team to some extent). In addition, the proposed educational / supervisory tools are as follows:

- books, etc.),

- $\quad$ audiovisual material (slides, charts, etc.),

- computers and internet.

- Finally, as far as the evaluation is concerned, it includes two areas (Fig.3):

- learners' assessment;

- evaluation of the program.

\section{Evaluation of Learners}

\section{Evaluation of Program}

\section{(totally)}

\section{Fig 3: Adult Education Program Content Structure}

\section{CONCLUSION}

The review of the literature, as well as the pedagogical design of the proposed program, showed that:

- Three-dimensional printing is a major revolution and its presence is becoming more intense in industry and education.

- The three-dimensional printing process starts by feeding the $3 \mathrm{D}$ printer with print material, making sure that the material is chosen to suit the needs of the print object. It then prepares, adjusts and clears the print surface, and once the digital 3D drawing is transferred to the printer, the machine automatically creates the desired 3D object.

- Low-cost innovation is facilitated as the cost of redesigning and reprinting is very low.

- Three-dimensional design already exists in the educational process, so trainees already have a relevant experience.

- Three-dimensional printing and the surrounding environment make it easier for learners to learn more complex concepts and provide them with new "tools".

- $\quad$ STEAM is a growing educational methodology that is increasingly used worldwide, based on its interdisciplinary approach and utilizing different fields of science (Physics, Technology, Engineering, Arts and Mathematics).

- The proposed curriculum was based on the philosophy of adult education programs.

\section{SECTIONS}

The heading of a section should be in Times New Roman 12point bold in all-capitals flush left with an additional 6-points of white space above the section head. Sections and subsequent sub- sections should be numbered and flush left. For a section head and a subsection head together (such as Section 3 and subsection 3.1), use no additional space above the subsection head.

\section{REFERENCES}

[1] European Commission, Brussels, BelgiumAdditive Manufacturing in FP7 and Horizon 2020: Report from the EC Workshop on Additive Manufacturing Held on 18 June 20142014, Additive Manufacturing in FP7 and Horizon 2020: Report from the EC Workshop on Additive Manufacturing Held on 18 June 2014 (2014).

[2] W. Simpson, C.B. Williams, M. Hripko, Preparing industry for additive manufacturing and its applications: summary \& recommendations from a National Science Foundation workshop, Addit. Manuf. 13 (2017) 166178, https://doi.org/10.1016/j.addma.2016.08.002.

[3] M. Despeisse, M. Baumers, P. Brown, F. Charnley, S.J. Ford, A. Garmulewicz, S. Knowles, T.H.W. Minshall, L. Mortara, F.P. Reed-Tsochas, J. Rowley, Unlocking value for a circular economy through 3D printing: a research agenda, Technol. Forecast. Soc. Change 115 (2017) 7584, https://doi.org/10.1016/j.techfore.2016.09.021.

[4] Lipson, H., Kurman, M., 2013. Fabricated: The New World of 3d Printing. John Wiley \& Sons, Indianapolis.

[5] Woodson, T.S., 2015. 3D printing for sustainable industrial transformation. Development 58 (4), 1-6.

[6] Beyer, C., 2014. Strategic implications of current trends in additive manufacturing. J. Manuf. Sci. Eng. 136 (6), 064701. https://doi.org/10.1115/1.4028599.

[7] Bureau of Labor Statistics, 2016. May 2015 National Occupational Employment and Wage Estimates. Retrieved February 28, 2017, from 〈https://www.bls.gov/oes/current/oes_nat.htm\#41-0000〉.

[8] Diegel, O., Singamneni, S., Reay, S., Withell, A., 2010. Tools for sustainable product design: additive manufacturing. J. Sustain. Dev. 3 (3), 68-75.

[9] [9] Gebler, M., Schoot Uiterkamp, A.J.M., Visser, C., 2014. A global sustainability perspective on 3D printing technologies. Energy Policy 74 (C), 158-167. https://doi.org/10.1016/j.enpol.2014.08.033.

[10] Giusti, L., 2009. A review of waste management practices and their impact on human health. Waste $\begin{array}{llll}\text { Manag. } & 29 & \text { (8), }\end{array}$ https://doi.org/10.1016/j.wasman.2009. 03.028.

[11] Grant, K., Goldizen, F.C., Sly, P.D., Brune, M.N., Neira, M., van den Berg, M., Norman, R.E., 2013. Health 
consequences of exposure to e-waste: a systematic review. Lancet Glob. Health 1 (6), e350-e361. https://doi.org/10.1016/S2214-109X(13)70101-3.

[12] Pastor, M., Sadd, J.I.M., Hipp, J., 2001. Which came first? Toxic facilities, minority movein, and environmental justice. J. Urban Aff. 23 (1), 1-21. https://doi.org/10.1111/07352166.00072.

[13] Tuan D. Ngoa, Alireza Kashania, Gabriele Imbalzanoa, Kate T.Q. Nguyena, David Huib, Additive manufacturing (3D printing): A review of materials, methods, applications and challenges, Composites Part B 143 (2018) 172-196.

[14] O. Ivanova, C. Williams, T. Campbell, Additive manufacturing (AM) and nanotechnology: promises and challenges, Rapid Prototyp J, 19 (5) (2013), pp. 353-364.

[15] M. Vaezi, H. Seitz, S. Yang, A review on 3D microadditive manufacturing technologies Int $\mathrm{J}$ Adv Manuf Technol, 67 (5) (2013), pp. 1721-1754.

[16] G. Bull, J. Chiu, R. Berry, H. Lipson, C. Xie, Advancing children's engineering through desktop manufacturing, in: J.M. Spector, M.D. Merrill, J. Elen, M.J. Bishop (Eds.), Handb. Res. Educ. Commun. Technol. 4th ed., Springer Science +Business Media, New York, 2014, pp. 675-688, , https://doi.org/10.1007/978- 1-4614-3185-5.

[17] Ford, S. Minshall, T. (2019). Invited review article: Where and how 3D printing is used in teaching and education. Additive Manufacturing 25, 131-150.

[18] J. Go, A.J. Hart, A framework for teaching the fundamentals of additive manufacturing and enabling rapid innovation, Addit. Manuf. 10 (2016) 76-87, https://doi.org/10.1016/j.addma.2016.03.001.

[19] C.B. Williams, C.C. Seepersad, Design for Additive Manufacturing Curriculum: A Problem- and ProjectBased Approach, 23rd Annu. Int. Solid Free. Fabr.
Symp.(2012) 81-92.

[20] A. Plemmons, Building a culture of creation, Teach. $\begin{array}{llll}\text { Libr. } & 41 \quad \text { (2014) } & 12-16 \quad \text { http:// }\end{array}$ search.proquest.com/docview/1548229289?accountid=81 94\%5Cnhttp://primo.unilinc.edu.au/openurl/ACU/ACU_ SERVICES_PAGE?url_ver=Z39.88-2004\&rft_ val_fmt=info:ofi/fmt:kev:mtx:journal\&genre $=$ article\&sid $=$ ProQ:ProQ\%3Aeducation \&atitle $=$ Building $+\mathrm{a}+\mathrm{Culture}+$ of + Cre.

[21] C.P. Pung, D. Morrow, Maker: A Practical Approach to Student Use of University Owned Rapid Prototype Machines, ASEE Annu. Conf. Expo. (2015), https://doi.org/10.18260/p.24446 p. 26.1109.1-26.1109.4

[22] A. Brown, Deanna; Vecchione, how to pack a room: 3D printing at albertsons library, Idaho Libr. 64 (2014).

[23] E. Buehler, S.K. Kane, A. Hurst, ABC and 3D: opportunities and obstacles to $3 \mathrm{D}$ printing in Special education environments, ASSETS' 14 Proc. 16th Int. ACM SIGACCESS Conf. Comput. Access. (2014) 107114, https://doi.org/10.1145/2661334.2661365

[24] S.K. Kane, J.P. Bigham, Tracking @ stemxcomet: Teaching Programming to Blind Students via 3D Printing, Crisis Management, and Twitter, SIGCSE' 14 Proc. 45th ACM Tech. Symp. Comput. Sci. Educ. (2014) 247-252, https://doi.org/10.1145/2538862.2538975

[25] Kokkos, A. (2005). Adult Education. Metexmio Edition, Athens (in Greek)

[26] Athanasiou, A. Baldoukas, A and Panaoura, R. (2014). (2014). Handbook for Adult Trainers. University of FREDERICK Edition, Leukosia, Cyprus.

[27] Karalis, Th. and Papageorgiou, H. (2012). Adult Education Employees Training. Educational Material, INE- $\Gamma \Sigma \mathrm{EE}$, Athens. 